\title{
"Eu Posso me Ver como Sendo Dois, Três ou Mais": Algumas Reflexões Sobre a Subjetividade Contemporânea
}

"I can see myself as being two or three or more": a few reflections on contemporary subjectivity

Daniela Romão-Dias \& Ana Maria

Nicolaci-da-Costa

Pontifícia Universidade Católica do Rio de Janeiro

\section{0}




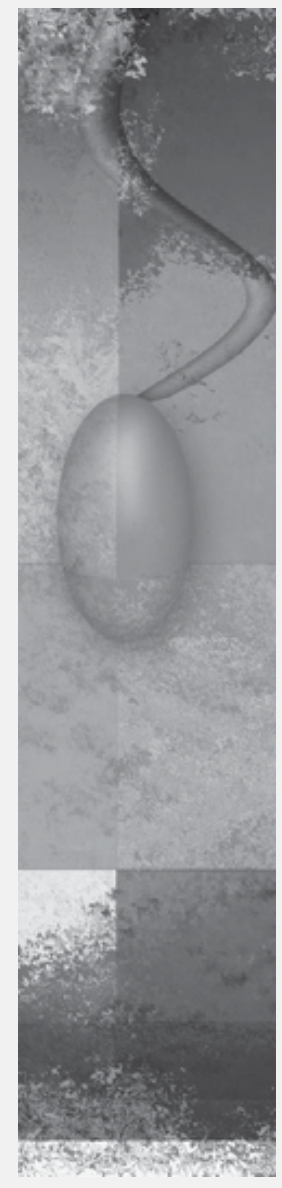

Resumo: O presente artigo tem como objetivo fazer algumas reflexões sobre as conseqüências subjetivas das transformações - sociais, econômicas, políticas, tecnológicas, etc. - que o mundo vem sofrendo nas últimas décadas. Para tanto, inicialmente, são discutidos os modelos propostos por Fredric Jameson e Sherry Turkle para descrever a subjetividade contemporânea. A seguir, é apresentada uma pesquisa realizada com usuários brasileiros da internet, que é considerada uma das condições de possibilidade da realidade de nossos dias. Dos resultados, emergem dois grupos de usuários com características bastante diferentes. Tais características são analisadas à luz das concepções teóricas de Jameson e Turkle.

Palavras-chave: internet, subjetividade, multiplicidade, fragmentação.

Abstract:The present paper aims at developing a few reflections on the subjective consequences of the transformations - social, economical, political, technological, etc. - that the world has been facing in the last decades. For this purpose, the models proposed by Fredric Jameson and Sherry Turkle to describe contemporary subjectivity are presented. This presentation is followed by the report of an investigation carried out with Brazilian users of the internet, which is considered one of the conditions of possibility of the reality in our days. Two groups of users with very different characteristics emerge from its results. Such characteristics are analyzed in reference to Jameson's and Turkle's theoretical conceptions.

Key words: internet, subjectivity, multiplicity, fragmentation.
Desde as últimas décadas do século $\mathrm{XX}$, o mundo vem passando por um processo de mudança radical que tem gerado uma grande efervescência intelectual (Leitão, 2003; Leitão \& Nicolaci-da-Costa, 2003). Como em outros momentos de transformação radical e acelerada (ver Nisbet, 1966), é grande o número de intelectuais de diferentes origens disciplinares que investigam os diversos aspectos desse processo de mudança a partir de pontos de vista também diversos.

Vários desses analistas - geralmente sociólogos e filósofos - investigam as transformações contemporâneas quase que exclusivamente do ponto de vista das conseqüências sociais geradas pelo chamado processo de globalização e pelo capitalismo flexível (Lyotard, 1998; Anderson, 1998; Harvey, 1999; Vattimo, 1996; Giddens, 1995). Outros, tal como Castells (1999) e Lévy (1998; 1996), analisam o mesmo conjunto de transformações atribuindo ao surgimento e à difusão das novas tecnologias digitais um papel determinante em sua gestação.

Por conta de seus objetivos de amplo escopo, independentemente da ótica adotada, quase todos esses estudos deixam de fora as conseqüências de maior interesse para a área da Psicologia: aquelas que dizem respeito à subjetividade.
As autoras agradecem o apoio dado pelo CNPq, sob a forma de bolsa de doutorado para a primeira autora e de produtividade em pesquisa para a $s e g u n d a$." 
São relativamente poucos os autores que procuram, nas transformações sociais contemporâneas, as raízes de transformações subjetivas. Dentre eles, destacam-se Sennett (1999), Bauman (1998) e Jameson (1993, 1995, 1997).

Há algumas semelhanças nos trabalhos desses três autores. A primeira se refere ao fato de que suas análises raramente atingem o nível de profundidade desejável para uma compreensão psicológica da transformação em curso, o que seria de se esperar, dado que os dois primeiros autores são sociólogos e o terceiro, crítico de arte. (Mesmo assim, seus trabalhos são muito instigantes e vêm sendo usados por psicólogos como ponto de partida para investigações das conseqüências psicológicas do atual processo de mudança.) Já a segunda semelhança está diretamente relacionada ao fato de que, ao contrário de Castells e Lévy, nenhum dos três atribui às tecnologias digitais um papel central nas mudanças contemporâneas.

Há, no entanto, uma importante diferença entre os trabalhos realizados por Sennett e Bauman e aquele desenvolvido por Jameson. Para começar, Jameson tem uma visão mais positiva do que Sennett e Bauman no que diz respeito ao que vem acontecendo com os homens e mulheres contemporâneos. Além disso, enquanto Sennett e, principalmente, Bauman recorrem a metáforas cotidianas como a de nômades, turistas, vagabundos, etc. - para dar conta das características subjetivas desses mesmos homens e mulheres, Jameson chega a propor um modelo de estrutura subjetiva calcado nas idéias de Lacan.

A positividade da abordagem de Jameson não passou despercebida aos olhares atentos de uma psicóloga norte-americana, autora de um trabalho pioneiro de investigação das características psicológicas que vêm sendo geradas pelas transformações sociais em curso, usando, para isso, a via das novas tecnologias digitais. Essa psicóloga é Sherry Turkle, professora do MIT, que, em 1995, publicou o livro Life on the Screen, no qual relata os resultados de uma pesquisa que tem como ponto de partida o modelo de subjetividade proposto por Jameson (1993, 1995, 1997). Utilizando-se desse modelo e dos resultados de uma das primeiras pesquisas sobre os impactos da internet sobre seus usuários norteamericanos, Turkle propõe um modelo alternativo ao de Jameson.

No que se segue, em um primeiro momento, serão apresentadas as características da organização subjetiva atual de acordo com cada um desses modelos. Posteriormente, será apresentada uma pesquisa realizada com usuários brasileiros. Os resultados desta serão discutidos tomando os modelos de Jameson e Turkle como referência.

\section{Disjunção esquizofrênica: a subjetividade pós-moderna de Jameson}

Ao longo de sua obra, Jameson (1993, 1995, 1997) descreve, em detalhes, as características macro que atribui à era atual, tais como fragmentação, superficialidade, heterogeneidade de discursos e espacialização do tempo. Diferentemente de muitos autores, no entanto, a partir dessas características, que dizem respeito à política, à economia, à cultura, às estruturas e dinâmica sociais, Jameson procura pensar o micro - no caso, o psicológico - e chega a propor um novo modelo de organização subjetiva. Para fazer isso, ele lança mão de um procedimento singular: elege algumas características da pós-modernidade, principalmente aquelas que dizem respeito à superficialidade e à fragmentação - que vê como centrais à contemporaneidade - e transpõe-nas para o campo da subjetividade. Tentemos acompanhar a linha mestra do seu raciocínio. 
De acordo com Jameson (1997), a era pósmoderna é marcada por uma superficialidade que se opõe à profundidade da era que a antecedeu - a modernidade. Um dos exemplos que dá se refere a uma obra de arte. Enquanto, na modernidade, uma obra de arte freqüentemente trazia em si significados ocultos e profundos, na pós-modernidade, uma obra de arte, no mais das vezes, não tem significações ocultas. É simplesmente aquilo que, de imediato, parece ser.

Na visão de Jameson, outra importante característica da pós-modernidade é a fragmentação. Para ele, a era pós-moderna não pressupõe a universalidade dos discursos característica da era moderna. Ao contrário, não parece haver, na pós-modernidade, o pressuposto da existência de uma verdade absoluta, mas, sim, o pressuposto de que existem verdades relativas. Assim sendo, na medida em que se pressupõe que não haja uma verdade que justifique a universalização dos discursos, o que resta são discursos fragmentados e heterogêneos coexistindo em uma mesma época.

Apoiado nessas noções de fragmentação e de superficialidade, Jameson tenta fazer a ponte entre o plano macro (social) e micro (psicológico). Para isso, recorre à categoria nosológica da esquizofrenia, mais especificamente, à esquizofrenia conforme proposta por Jacques Lacan (ver Lacan, 1985, 1998 e Calligaris, 1989). Tal recurso, embora Ihe forneça um modelo de funcionamento psíquico, infelizmente lhe cria problemas. Como já mencionado, Jameson tem como objetivo descrever a estrutura e a dinâmica internas que caracterizam positivamente a subjetividade contemporânea e o termo esquizofrenia inevitavelmente remete à idéia de patologia. Por esse motivo, Jameson tenta separar as características da esquizofrenia de suas implicações patológicas. Sua proposta não é a de ver o sujeito pós-moderno como um sujeito doente, mas, sim, como um sujeito estruturalmente fragmentado, como se pode perceber pela citação abaixo:

“(...) Lacan descreve a esquizofrenia como sendo a ruptura na cadeia dos significantes, isto é, as séries sintagmáticas encadeadas de significantes que constituem um enunciado ou um significado. (...) Quando essa relação se rompe, (...) então temos a esquizofrenia sob a forma de um amontoado de significantes distintos e não relacionados. A conexão entre esse tipo de disfunção lingüística e a psique do esquizofrênico pode ser entendida por meio de uma proposição de dois níveis: primeiro, a identidade pessoal é, em si mesma, efeito de uma certa unificação temporal entre o presente, o passado e o futuro da pessoa; em segundo lugar, essa própria unificação temporal ativa é uma função da linguagem (...). Se [na pós-modernidade] somos incapazes de unificar o passado, o presente e o futuro da sentença, então somos também incapazes de unificar o passado, o presente e o futuro de nossa própria experiência biográfica, ou de nossa vida psíquica" (Jameson, 1997, pp. 52-3).

Na visão de Jameson, portanto, a era pósmoderna dá ao sujeito a sensação de estar vivendo em um eterno presente (um presente que outros autores chamam de presente "espacializado"; a esse respeito, ver Bauman, 1998, e Harvey, 1999). Essa percepção de eterno presente que os sujeitos da era pósmoderna parecem experimentar é fundamental para que Jameson pense na esquizofrenia como metáfora da subjetividade atual, isso porque, de acordo com alguns autores (ver Pankow, 1989), uma das características da esquizofrenia é a perda da capacidade de conexão temporal e o conseqüente sentimento de viver em um eterno presente.

Outro aspecto importante da subjetividade descrita por Jameson diz respeito ao que ele denominou fim do modelo subjetivo da "mônada". A palavra "mônada" vem do latim monades, que quer dizer "único", e foi inventada, no século XVI, por Giordano Bruno
"Se [na pósmodernidade] somos incapazes de unificar o passado, o presente e o futuro da sentença, então somos também incapazes de unificar o passado, 0 presente e o futuro de nossa própria experiência biográfica, ou de nossa vida psíquica"

(Jameson, 1997, pp. 52-3). 
(ver Lopes, 1998). A mônada pode ser entendida como uma substância simples, que não pode ser dividida. À característica de indivisibilidade da mônada, Jameson acrescenta outra - a de centralidade - quando se refere à subjetividade predominante na era moderna. Segundo Jameson, nessa era, o sujeito era percebido (por si mesmo e pelos outros) tal qual uma mônada: indivisível e dotado de um cerne, de uma instância central - ou de uma "miragem" desta -que não parece existir na organização subjetiva pós-moderna. Ainda de acordo com Jameson, o que parece existir, nos dias de hoje, é exatamente o oposto disso: descentramento e fragmentação.

Falar sobre o "fim da mônada" é, para Jameson, o mesmo que falar sobre o "fim do ego". Por princípio, o fim do ego acarretaria uma superficialidade que, também na visão de Jameson, é típica da subjetividade pósmoderna. Para subsidiar sua argumentação, Jameson alega que sentimentos profundos, como os de anomia, ansiedade e alienação, são típicos da subjetividade moderna, mas não da pós-moderna. O sujeito pós-moderno, sem "a presença de um ego para encarregar-se de sentir" (Jameson, 1997, p. 43), tem seus sentimentos substituídos por "intensidades" uma espécie de versão superficializada dos sentimentos.

Apesar de dedicar relativamente poucas páginas ao tema da subjetividade, as reflexões feitas por Jameson a seu respeito são bastante provocativas. Tão provocativas que, como já foi dito, serviram de ponto de partida para as investigações levadas a cabo por Turkle (1997).

\section{Múltiplos selves: a subjetividade segundo Turkle}

Como já foi dito, em seu livro Life on the Screen (1997), Turkle parte de algumas reflexões de Jameson para lançar suas idéias sobre a subjetividade atual.

Ainda que Jameson dê pouco destaque ao papel das tecnologias digitais no panorama atual, Turkle considera que essas tecnologias possuem características muito semelhantes àquelas que ele atribui à pós-modernidade. A esse respeito, Turkle diz:

"Uma década atrás, Fredric Jameson escreveu um clássico artigo sobre o significado do pósmodernismo. Em sua caracterização do pósmodernismo, ele incluiu a prevalência da superfície sobre o profundo, da simulação sobre o real, do jogo sobre a seriedade, muitas das mesmas qualidades que caracterizam a nova estética do computador. Naquele tempo, Jameson notou que o pós-modernismo era carente de objetos que pudessem representálo. A turbina, a chaminé, os canos e a esteira de rolagem do final do século XIX e início do XX foram poderosos objetos para pensar a natureza da modernidade industrial. (...) Jameson sugeriu que era preciso uma nova estética do mapeamento cognitivo, um novo modo de pensamento espacial, que nos permitiria ao menos registrar a complexidade do nosso mundo. Uma década depois de Jameson ter escrito esse ensaio, o pósmodernismo encontrou seus objetos básicos. (...) os objetos do pós-modernismo agora existem fora da ficção científica. Eles existem nas informações e conexões da internet, no World Wide Web [www] e nas janelas, ícones e camadas do computador pessoal. (...) Tudo isso é vida na tela. Com esses objetos, as idéias abstratas nos escritos de Jameson sobre o pósmodernismo tornaram-se recentemente acessíveis, até mesmo, consumíveis" (Turkle, 1997, pp. 44-5, nossa tradução).

Além de fazer essa analogia entre as novas tecnologias e a descrição da pós-modernidade feita por Jameson, Turkle deixa claro que está de acordo com algumas outras considerações e posturas desse autor no que diz respeito ao sujeito contemporâneo. Assim como Jameson, 
Turkle acredita no fim da unidade e da centralidade típicos da organização subjetiva da modernidade. E, também tal como Jameson, Turkle parte de um quadro clínico clássico da Psiquiatria para propor uma nova organização subjetiva. (Enquanto, como já visto, Jameson parte da esquizofrenia, Turkle, como será abordado adiante, parte do transtorno de personalidade múltipla.)

Na citação abaixo, por exemplo, Turkle parece justificar por que concorda com Jameson quando este declara o fim do modelo subjetivo da mônada. Em suas próprias palavras:

"Fredric Jameson escreveu que, num mundo pós-moderno, o sujeito não é alienado, mas fragmentado. Ele explicou que a noção de alienação supõe um self unitário e centrado que poderia ser perdido. Mas se, como um pós-moderno vê, o self é descentrado e múltiplo, o conceito de alienação cai por terra.

(...) Na simulação [que a realidade virtual permite], a identidade pode ser fluida e múltipla, um significante não mais aponta claramente para algo que é significado, e a interpretação é menos provável proceder pela análise do que pela navegação no mundo virtual" (Turkle, 1997, p. 49, nossa tradução).

Uma outra semelhança entre Jameson e Turkle é a de que, tal como aquele, esta, além de argumentar que a organização subjetiva típica da modernidade está sofrendo transformações, também propõe um novo modelo de subjetividade.

Contudo, diferentemente de Jameson, que deriva seu modelo subjetivo de análises teóricas, Turkle se baseia nos resultados de uma extensa pesquisa por ela realizada com usuários da internet-e, mais especificamente, de jogos interativos denominados MUDs (Multi-User Domains) -na medida em que atribui um papel determinante às novas tecnologias na construção de novas organizações subjetivas. Tendo por base os resultados dessa pesquisa, Turkle esboça um modelo da subjetividade contemporânea alternativo ao de Jameson. Para isso, entretanto, tal como esse autor, ela também recorre à metáfora de uma categoria nosológica psiquiátrica. A diferença é a de que, ao invés de recorrer à imagem da esquizofrenia, Turkle prefere usar a de transtorno de personalidade múltipla. Vejamos o que ela própria escreve:

“(...) o estudo do transtorno de personalidade múltipla pode começar a fornecer formas de pensar sobre selves saudáveis como nãounitários, mas com acesso fluido por seus aspectos. Portanto, em adição aos extremos de um self unitário e transtorno de personalidade múltipla, podemos imaginar um self flexível" (Turkle, 1997, p. 261, nossa tradução).

Ou seja, apesar das suas afinidades com as idéias de Jameson, ao escolher a metáfora do transtorno de personalidade múltipla para o seu modelo subjetivo, Turkle já dá evidências de discordar dele em pelo menos alguns pontos (pontos importantes, como será argumentado abaixo), isso porque, embora tanto a esquizofrenia quanto o transtorno de personalidade múltipla sejam classificações tradicionais da Psiquiatria, suas características são muito diferentes.

Dado que Jameson e Turkle concordam que o sujeito contemporâneo é descentrado, a diferença que realmente importa, no que diz respeito ao argumento que vimos desenvolvendo, é aquela relativa à multiplicidade de personalidades característica do transtorno de personalidade múltipla em oposição à fragmentação do eu típica da esquizofrenia.

Enquanto Jameson diz que, na organização subjetiva atual, o eu é descentrado e fragmentado, Turkle afirma que "o self [eu] é descentrado e múltiplo" (Turkle, 1997, p. 49, nossa tradução).
"(...) Na simulação [que a realidade virtual permite], a identidade pode ser fluida e múltipla, um significante não mais aponta claramente para algo que é significado, e a interpretação é menos provável proceder pela análise do que pela navegação no mundo virtual"

(Turkle, 1997, p. 49, nossa tradução). 
Quando Jameson fala de um sujeito fragmentado, ele caracteriza esse sujeito como um eu que está dividido em vários pedaços, várias partes, isto é, vários fragmentos. É como se, em algum momento, esse sujeito tivesse tido um eu único e centralizado, mas, agora, essa unidade e centralidade tivessem sido substituídas por uma divisão, uma fragmentação. Já no caso de Turkle, é como se esse eu único e centralizado, ao invés de se fragmentar, se multiplicasse. Assim, o sujeito atual, para Turkle, ao invés de ser composto de várias partes, vários pedaços de um todo, é constituído de vários todos, vários selves.

Além de Turkle caracterizar o sujeito atual como aquele que possui múltiplos selves, ela ainda acrescenta uma outra característica a essa multiplicidade: a simultaneidade. Para Turkle, portanto, o sujeito contemporâneo possui múltiplos selves que agem simultaneamente. Para que melhor se compreendam esses selves simultâneos, Turkle faz uma analogia com o sistema operacional Windows, usado nos computadores pessoais. A autora lembra que, muitas vezes, quando se utiliza o Windows, várias "janelas" são abertas para diferentes finalidades. Pode-se estar em um programa de bate-papo e ter abertos, na tela do computador, outros programas, como editores de textos, jogos e navegadores. Dessa forma, é possível se passar da sala de bate-papo para o navegador e para o jogo com tanta naturalidade e rapidez que se tem a sensação de estar realizando várias atividades ao mesmo tempo. No caso dos múltiplos selves, algo análogo a isso acontece. Para Turkle, é tão rápido e fácil passar de um self a outro que é como se esses selves estivessem sempre à disposição, como as janelas abertas do Windows.

Selves múltiplos que agem simultaneamente e sem uma instância central de agenciamento, essas parecem ter sido as principais conclusões a que Turkle chegou sobre a organização subjetiva atual.
Para Turkle chegar a esse modelo de subjetividade, ela aliou seus estudos sobre a pós-modernidade - e sobre as idéias de Jameson - a uma pesquisa de campo bastante aprofundada com usuários da internet. Aqui, com pretensões certamente menores, também tentaremos ganhar algum insight sobre a subjetividade contemporânea a partir da presente discussão teórica e dos resultados de uma pesquisa realizada com usuários brasileiros da internet.

\section{Investigando a subjetividade contemporânea: uma pesquisa brasileira}

Com o objetivo de investigar as transformações subjetivas contemporâneas a partir do contato com a internet, foram entrevistados 16 usuários (homens e mulheres) com idades entre $19 \mathrm{e}$ 46 anos. Todos eram brasileiros e faziam uso de programas que permitem conversas em tempo real, como, por exemplo, os programas de bate-papo, o ICQ (I Seek You) e semelhantes.

\section{Coleta de dados}

Para a coleta de dados, escolheu-se realizar entrevistas em profundidade, tendo como guia um roteiro composto de itens, a partir dos quais deveriam ser formuladas perguntas abertas durante a entrevista (esse procedimento visava a evitar que as perguntas soassem muito formais - ver Nicolaci-da-Costa, 1989). Esses itens deveriam ser abordados em todas as entrevistas, mas não necessariamente na mesma ordem, isso porque era importante que fosse preservada a naturalidade de uma conversa informal para que os sujeitos pudessem se sentir descontraídos e pouco defensivos. Se necessário, todas as perguntas poderiam ser complementadas com solicitações de esclarecimento ou aprofundamento, tais como "por quê?", "como?" ou "pode explicar melhor?". Seguemse todos os itens: 
(1) Investigar como é o cotidiano do entrevistado (não necessariamente na rede). (2) $\mathrm{Na}$ internet, verificar se o entrevistado já ficou muito tempo conectado e, em caso positivo, fazendo o quê? (3) Investigar o que o entrevistado gosta de fazer na internet. (4) Investigar como são suas relações com as pessoas na internet. Investigar se o entrevistado faz alguma diferença entre essas relações online e as que mantém fora da internet. (5) Investigar como o entrevistado usa seus apelidos (nicks) em diferentes programas. (6) Investigar como o entrevistado se sente na rede por comparação a fora da rede. Caso haja diferenças nesses sentimentos, investigar quais são. (7) Verificar se o entrevistado já encontrou pessoalmente alguém que tenha conhecido pela internet. Em caso positivo, perguntar como foi a experiência. Em caso negativo, explorar por que isso nunca aconteceu. (8) Pedir ao entrevistado que defina o que entende por realidade virtual. (9) Pedir ao entrevistado que defina o que entende por realidade "real". (10) Perguntar ao entrevistado quais são as vantagens e desvantagens da realidade virtual. (11) Perguntar o que ele procura na internet.

\section{Procedimentos}

Em um primeiro momento, foram realizadas entrevistas-piloto, presenciais, a fim de testar o roteiro. Nessa etapa piloto, os sujeitos abordados revelaram que se sentiriam mais confortáveis se pudessem ser entrevistados através da internet. Testado o roteiro, seguiuse a sugestão desses sujeitos, já que era desejado que os entrevistados se sentissem tão à vontade quanto possível.

Após a etapa-piloto, foi iniciado um recrutamento dos sujeitos por meio da própria internet. Assim, foi redigida uma mensagem, a ser enviada por e-mail, na qual havia um pequeno texto que convidava o destinatário a comentar um trecho provocativo inspirado em um depoimento contido no livro de Sherry
Turkle (1997). Logo a seguir, perguntava-se ao destinatário se ele estaria disposto a conceder uma entrevista em tempo real através de um programa interativo chamado ICQ. Abaixo segue-se um trecho do e-mail enviado (observe-se o quanto é informal):

"Leia esse depoimento e comente-o da forma mais livre que puder. Vale qualquer coisa que sua imaginação mandar. Não há forma ou limite de linhas!

'Sinto que, quando estou no IRC, posso ser qualquer coisa. $\mathrm{E}$, no meio de todas aquelas janelas e canais, onde sou linda, loura, homem, mulher, feia, criança ou velha, sinto que essas janelas são parte da minha vida. E a vida real é mais uma, dentre muitas janelas possíveis."'

Esse e-mail foi enviado a amigos e conhecidos, que o redirecionaram para outros amigos, bem como para listas de discussão. Ao todo, 35 pessoas responderam ao e-mail. Destas, 16 concederam a entrevista via ICQ.

Essas entrevistas foram salvas no próprio ICQ e em disquete a fim de serem analisadas. Os depoimentos que apresentaremos abaixo foram extraídos dessas entrevistas sem modificações, de forma que foram mantidos todos os erros gramaticais, neologismos e abreviações. Além disso, todos os nomes e nicks dos sujeitos foram alterados para a garantia de seu anonimato.

\section{Análise do material}

O material foi analisado a partir das técnicas de análise de discurso, tal como descritas por Nicolaci-da-Costa $(1994,1989)$. De acordo com esse método, foram realizadas análises inter-sujeitos e intra-sujeitos. Na etapa de análise inter-sujeitos, foi examinado o que os sujeitos responderam a cada item/pergunta do roteiro. Foram, também, agrupadas as respostas semelhantes. Posteriormente, foi realizada a análise intra-sujeitos, na qual cada 
entrevista foi examinada separadamente, de modo a permitir a verificação de possíveis inconsistências e contradições nos depoimentos de cada um dos sujeitos. Quando essas inconsistências ou contradições foram encontradas, todas as entrevistas foram novamente comparadas entre si (análise inter-sujeitos) a fim de descobrir se tais inconsistências ou contradições eram idiossincráticas ou se revelavam algum conflito comum a muitos entrevistados (ou mesmo todos). Após essas etapas, foi possível termos uma visão ampla e, ao mesmo tempo, aprofundada, do discurso dos entrevistados.

\section{Principais resultados}

Sem exceção, todos os entrevistados relataram ter mais facilidade de se expressar quando estão na rede do que quando interagem presencialmente com outra pessoa. Todos os sujeitos também disseram ter tido, em algum momento, a experiência de conversar pela internet com alguém que não conheciam anteriormente. Essa experiência de relação interpessoal pela internet trouxe, entretanto, sentimentos diferentes para os entrevistados. Por conta dessas diferenças, os sujeitos tiveram que ser divididos em dois grupos.

\section{Apresentando o primeiro grupo}

O primeiro grupo é pequeno. Dele fazem parte somente quatro dos dezesseis entrevistados. Esses sujeitos, ao travarem contato com a internet, descobriram os canais de chat, por meio dos quais podiam conversar com conhecidos e desconhecidos. Chegaram a pensar que era mais fácil iniciar uma conversa pela internet do que presencialmente. Perceberam, no entanto, que essa facilidade não os levava a relações que considerassem sólidas e verdadeiras. Como diz uma entrevistada: "na rede a coisa toda é muito superficial. nã minha opinião seria o ideal só para o passo preliminar de uma futura amizade (...) a internet é como uma máscara ou um murode proteção, como ir além da superficialidade escondido atrás de tanta maquinaria e fios? não existe um contato real, palpável, olho no olho" (Cris, 27 anos, jornalista e estudante de cinema).

Os membros desse primeiro grupo sentem falta do contato "olho-no-olho". Relatam, inclusive, ter medo de revelar dados pessoais pela internet, pois, sem o contato presencial, julgam ficar sem nenhuma referência a respeito do interlocutor. Muitos se dizem incomodados com a possibilidade de seus interlocutores mentirem. Justamente por conta disso, alguns integrantes desse grupo revelam ter tentado encontrar-se pessoalmente com algumas pessoas que conheceram na rede. No entanto, quando esses contatos aconteceram, isso não os deixou mais aliviados. Pelo contrário, a decepção com esses encontros foi tão grande que lhes serviu de confirmação de que não é possível confiar em relações iniciadas na rede. $\mathrm{Na}$ realidade, a decepção com as relações iniciadas pela internet é vista por eles como inevitável por conta de dois fatores. Primeiramente porque, para eles, não é possível manter um contato pessoal verdadeiro estritamente pela rede (eles acham que as pessoas podem mentir). Em segundo lugar, eles são da opinião de que, se o contato deixa de ser somente "virtual" e passa a ser presencial, mesmo que o conhecido virtual não tenha mentido a seu respeito, ainda assim a relação não vai adiante, isso porque as expectativas que os membros do primeiro grupo têm em relação ao conhecido virtual são tantas (em relação ao tipo físico, por exemplo), que eles acabam se decepcionando, já que tais expectativas raramente correspondem à realidade. A respeito do "fracasso" das relações interpessoais iniciadas na rede, Bruno e Rita têm relatos interessantes e que expressam bem o que os membros de seu grupo sentem: 
"Acho que [as relações travadas pela internet] não são muito verdadeiras, muita coisa pode ser inventada e às vezes não pode ser detectada pela rede... (...) na rede não tem o olhar, pode se manter um certo anonimato, fora da rede acho mais difícil [manter esse anonimato]..." (Bruno, 23 anos, estudante de Informática).

"a primeira vez que fiz isso [encontrar uma pessoa que havia conhecido na Internet], descobri que muito da pessoa que vc [você] conhece na rede é vc mesma que imagina. teve um cara, lá em Brasília ainda, com quem eu conversava (...) e eu descobri que ele era irmão de um cara que eu conhecia, que era super amigo de uma amiga minha. então resolvi conhecer ao vivo. apesar de eu ter visto uma foto, achei o cara esquisitíssimo ao vivo" (Rita, 25 anos, jornalista).

De acordo com esse primeiro grupo, seja por conta das mentiras que os interlocutores podem contar, seja porque os próprios sujeitos idealizam muito um encontro "olho-no-olho", as relações interpessoais que se iniciam na rede não vingam. Grosso modo, a impressão que se tem é que, para os representantes desse grupo, se as pessoas não são, fora da rede, exatamente o que elas dizem ser dentro dela, há alguma falsidade em jogo. Essa falsidade é insuportável para eles. O mesmo não acontece com os membros do segundo grupo. Estes lidam com as diferenças entre o online e o offline de forma muito diversa, como será exposto a seguir.

\section{Apresentando o segundo grupo}

O segundo grupo é composto pela grande maioria dos entrevistados, totalizando doze integrantes. Como já foi dito, uma das poucas semelhanças entre os dois grupos diz respeito ao fato de seus integrantes gostarem de utilizar salas de bate-papo e outros programas interativos. Para o segundo grupo, no entanto, o contato interpessoal via rede revela-se muito menos complicado do que para o primeiro.
As falas de Guiga e Quinhodantas mostram a facilidade que esses sujeitos têm de fazer amigos pela internet:

“minhas amizades são sempre feitas no mIRC [programa de bate-papo]. são tres tipos: os reais, os virtuais e os virtuais q [que] tornaramse reais. $\mathrm{Hj}$ [hoje], quase todos os amigos que tenho, conheci noa internet..desde namoro, ate amizades firmes. Cinheci todos atraves da rede, conheci pessoalmente e nos tornamos grandes amigos" (Guiga, 22 anos, empresário virtual).

"Hoje vou encontrar minha namorada [na Internet] Mas, se nào estivesse namorando poderia vir procurar gente num espaço onde sei que vou tentar falar com essa gente e não apenas olhar. (...) Eu procuro viver a vida dentro da realidade que existe, e a rede é real" (Quinhodantas, 24 anos, psicólogo).

Tal como os membros primeiro grupo, contudo, os integrantes do segundo grupo sentem necessidade de encontros presenciais com seus amigos virtuais. A diferença em relação ao primeiro grupo está em como os integrantes do segundo vivenciam esses encontros. Segundo Margot e Gut:

"Foi sempre muito bom [encontrar os amigos virtuais]. Aquela expectativa...mas sempre digo que nunca me decepcionei. Todas as pessoas que conheci no real, embora possam ter me surpreendido prq [porque] fisicamente eram diferentes do que imaginava, a postura tb [também]...eram do bem. A emoção de encontrar é muito boa. Tb não encontro c/ qualquer pessoa. Quando resolvo encontrar é prq já tenho um vínculo forte, um desejo de conhecer" (Margot, 48 anos, psicóloga).

"Muito esquisito!!! [encontrar os amigos virtuais]. Eu imaginava as pessoas totalmente diferentes (...) Mas foi ótimo. (...) Por mais que alguem te fale como eh [é] e q vc conheça a pessoa virtualmente, o rosto dela, os gestos...
"Hoje vou encontrar minha namorada [na Internet] Mas, se nào estivesse namorando poderia vir procurar gente num espaço onde sei que vou tentar falar com essa gente e não apenas olhar. (...)" 
eh tudo muito diferente na vida real. A gente nunca consegue imaginar alguma coisa proxima da realidade. Porque a Internet naum [não] porporciona tudo, ne? Vc tem um lampejo do que a pessoa eh, mas nunca o todo. Eh muito diferente. Mas também tem suas vantagens" (Gut, 22, mestranda em Comunicação).

Como é possível notar, os sujeitos do segundo grupo também têm expectativas em relação a esses encontros presenciais. Eles também percebem diferenças entre o que se passa on e offline. Eles, entretanto, não consideram falso o que se passa na rede. Ao contrário, parecem tomar como verdade tanto o que ocorre online quanto o que ocorre offline. Parece que partem da premissa de que tudo é real até que se prove o contrário.

Essa premissa de que "tudo é real até que se prove o contrário" diferencia-os ainda mais do primeiro grupo, isso porque os sujeitos do segundo grupo relatam que podem agir, pensar e, até mesmo sentir de forma diferente quando estão online e quando estão offline. E mais, um representante do segundo grupo pode interagir com as pessoas de formas distintas quando está online e quando está offline, sem que isso queira dizer que esse sujeito falta com a verdade quando está on ou offline.

Margot, assim como muitos dos outros entrevistados, utiliza um nome fictício na rede e, apesar de não achar que esse nome é uma espécie de máscara, observa diferenças entre seu comportamento dentro e fora da internet. Já Quinhodantas, nem nome fictício utiliza, mas acredita que, quando está na internet, pode ser diferente de quando está fora dela. Os depoimentos desses dois entrevistados revelam, de forma clara, as distinções que os integrantes desse grupo fazem entre o que sentem quando estão on e offline:

"Eu detesto o margot...risos... no início achava que tinha que manter o anonimato, era paranóica que soubessem quem era. margot então não tem nada a ver comigo. Disfarce mesmo... Mas como passei a ser conhecida assim, não mudo. (...) Sinto que [na Internet] exercito este lado criança, menos compromissado, sem preocupações de ser politicamente correta. Sou muito assim no real tb. Tô sempre alegre.Mas no chat posso ser ainda mais criativa e descompromissada. (...) Uma amiga nossa do chat entrou para a Faculdade. (...) Fomos comemorar e levei de presente um estojo destes de meninas, rosa, com tudo bonitinho. Na amizade real, acho que não teria esta criatividade...risos" (Margot, 48 anos, psicóloga).

“Eu não invento personagens na rede, me sinto muito à vontade para ser eu, mais do que na vida aqui fora. Eu é que fico diferente diante desse outro na rede. não sei se as pessoas me recebem diferentemente na NET, eu é que me sinto menos tolhido ou cobrado diante do outro e consigo abordar" (Quinhodantas, 24 anos, psicólogo).

Há, no entanto, alguns entrevistados desse grupo que, além de se sentirem diferentes on e offline, também relatam usos muito curiosos de nicks. Ao contrário de Margot e Quinhodantas, que usam apenas um nick na rede, esses outros usuários possuem vários nicks. Escolhem situações específicas para utilizá-los e criam profissões, gênero e características próprias para cada um deles. Esses sujeitos não foram a maioria dos membros do segundo grupo, muito menos a maioria dos entrevistados. Seus depoimentos, contudo, merecem ser examinados com cuidado, pois oferecem pistas para a compreensão de algumas características centrais do segundo grupo. Como não é possível reproduzir os depoimentos de todos esses entrevistados, foram escolhidos trechos das entrevistas de dois deles: Morpheus e Sr. Mistério.

Morpheus usa nicks na internet para "fingir" que é outra pessoa. Inventa nomes, profissões, 
tipos físicos. Em seu depoimento, apresentado abaixo, sugere estar "se divertindo às custas dos outros":

"A internet permite a vc ser uma pessoal completamente diferente do que vc eh normalmente ja que vc pode falar com pessoas que nao te conhecem pessoalmente ne. voce pode se fazer passar por outro tipo de pessoa (uma outra personalidade) (...) se vc malipular essas informações pode passar a impressao que vc quiser para a outra pessoa vc pode ser quem vc quiser ser (...). ja ao vivo vc nao pode fazer esse tipo de coisa ate pq o seu proprio fisico te trai. [você já fez isso, quer dizer, brincar de ser outra pessoa na net?] Já. Costumava fazer isso pra passar o tempo (...) e aí .... o show comecava :) [e como era esse show?] normalmente eu puxava papo com alguma minina do canal (...) e comecava a me fazer passar por alguem que eles queriam que eu fosse (tipo por um lutador de jiujitsu pras mininas que se amarram nisso) (...) o segredo da parada eh vc dar a "vitima" o que ela quer em termos de personalidade e ter atencao pra nao cair na sua propria mentira" (Morpheus, 23 anos, analista de sistemas júnior).

Como pode ser observado, Morpheus afirma utilizar a internet para brincar com as outras pessoas. Em outro momento de sua entrevista, no entanto, quando define o que é a "realidade virtual", dá a entender que a internet parece ser mais importante, para ele, do que um mundo de brincadeiras. Em suas próprias palavras:

“[realidade virtual é] um 'mundo' gerado por computador onde voce pode escolher todas as variaveis do ambiente que vc vai estar seria algo como poder estar num mundo onde quem manda eh vc. [realidade real é] um mundo onde vc controla $10 \%$ das variaveis :) isso eh vc nao esta no comando vc simplismente vive de acordo com as regras dele nao importa se vc gosta ou nao delas apesar de na realidade real vc ter que viver pelas regras eu tento me adaptar (ou melhor seria adaptar as regras :) ) para que eu me sinta o melhor possível a realidade virtual pra mim eh so uma extensao da minha realidade "real" desvantagens...da realidade virtual? nao vejo"(Morpheus, 22 anos, analista de sistemas júnior).

Passemos agora para o Sr. Mistério, que, fora da rede, apresenta-se como Henrique. Assim como Morpheus, ele faz uso de vários nicks. Ao contrário de Morpheus, todavia, ele não utiliza seus nicks para "se divertir às custas dos outros". Antes, porém, de revelar para quais finalidades o Sr. Mistério usa seus nicks, é importante entender um pouco como ele os cria:

"Em matéria de Internet, eu gosto de experimentar todos os recursos. Então, (...) soube dessa história de newsgroups. (...) Foi no meio [dos newsgroups] que eu desenvolvi um alter-ego chamado Grouxo, um personagem totalmente arbitrário, que saía agredindo uns e se aliando a outros sem o menor critério, além de ter uma opinião do contra. O interessante foi o seguinte: como o Grouxo estava apenas em busca de polêmica, arrumou dúzias de inimigos figadais e um bom punhado de admiradores(as). No fim, quando resolvi matar o Grouxo, já havia estabelecido contato com alguns do admiradores do Grouxo e explicado: "Olha, não sou nada disso não, é só um personagem, e tal". Acabei ficando amigo dessas pessoas, trocando e-mails e contando a vida toda online. [Como foi isso de brincar de ser outra coisa?] Bem, na verdade não foi como brincar de ser outra coisa, foi como brincar de ser escritor. Porque todas as opiniões do Grouxo eram possibilidades em minha mente, resultado de mil e dezesseis leituras sobre muita coisa (não sei se estou muito claro). Quer dizer, as opiniões dele, bem poderiam ser as minhas, mas não as defenderia com tanta ênfase assim" (Sr. Mistério, 32 anos, professor universitário).
" Foi no meio [dos newsgroups] que eu desenvolvi um alter-ego chamado Grouxo, um personagem totalmente arbitrário, que saía agredindo uns $e$ se aliando a outros sem o menor critério, além de ter uma opinião do contra". 
Além de Grouxo, o Sr. Mistério ainda revela algumas características de outros nicks seus, alguns já fora de uso:

"O primeiro [nick] foi White (...). White era sério e professoral. O segundo, Grouxo. O oposto de White. Caótico. Polêmico e incrível! - bem-humorado, debochado, sacana. O atual, Sr. Mistério, surgiu de uma discussão que resultou na morte do Grouxo. (...) Tb tenho outros nicks, mas, como ainda estão em uso, é melhor não divulgar... (...) O White era meio chato, matei-o sem muita dó. Já o Grouxo me causou alguma tristeza, mas eu mesmo já não agüentava o radicalismo anárquico do sujeito. O Sr. Mistério está funcionando bem para ICQ e para minha lista de discussão, uso para mensagens neutras, ou quando não quero me identificar em sites comerciais. Tenho mais um nick que uso para enviar cartas de protesto barra pesada para empresas, jornais e políticos, por isso é que não divulgo para você..." (Sr. Mistério, 32 anos, professor universitário).

O Sr. Mistério, de fato, parece utilizar bastante o que testa na rede. Ao invés de ter como foco brincar com os outros, o foco de Sr. Mistério parece ser o de testar a si mesmo. Chama, inclusive, seus nicks de "alteregos", como em uma das passagens acima. Esses nicks parecem servir para o Sr. Mistério ser uma espécie de cobaia de si mesmo. Ele cria os nicks, testa-os e incorpora, fora da rede, o que aprende por meio desses testes. Conforme ele explica:

"Eu diria que a Rede tem servido como um meio de reconhecer alguns potenciais adormecidos. Eu reconheço alguns comportamentos na Net que eu não teria pessoalmente, por timidez, ou por não me ocorrer! Como, na Net, a ansiedade é mais reduzida, noto que encontro soluções comportamentais bem melhores do que na vida real. Só que eu passo a incorporar essas soluções à vida real, passo a experimentá-las na prática fora da rede. Então, meu 'eu real' tende a se igualar ao 'virtual'. Em suma, não me vejo como duas pessoas diferentes. Vejo a Net como um laboratório de comportamentos" (Sr. Mistério, 32 anos, professor universitário).

Esses depoimentos tornam evidente que tanto o Sr. Mistério quanto Morpheus, bem como outros sujeitos, utilizam, de forma lúdica, seus nicks na internet. Morpheus talvez seja um pouco ingênuo ao pensar que está somente brincando na rede. Já o Sr. Mistério é suficientemente sagaz para integrar à vida "real" o que aprende na internet. O que ele, Morpheus e todos os membros do segundo grupo têm em comum, entretanto, é uma sensação de que, na rede, algo se passa que é diferente da realidade offline. A pergunta que se coloca é: o que essa sensação tem a dizer sobre a subjetividade dessas pessoas?

\section{Jameson, Turkle e os nossos resultados: uma breve discussão}

A maior diferença entre os dois grupos que emergiram desta pesquisa diz respeito às características subjetivas que seus membros tornaram visíveis, principalmente em seus depoimentos a respeito de relações interpessoais on e offline. Segue-se uma análise dessas características e de suas implicações para a discussão dos modelos de subjetividade apresentados anteriormente.

\section{Primeiro grupo: uma organização subjetiva moderna}

Os integrantes do primeiro grupo foram aqueles cujas relações interpessoais iniciadas na rede terminaram em experiências frustrantes. Para eles, a falta de referências concretas (nome "real", tipo físico, voz, cheiro, cor dos olhos e da pele, etc) característica da realidade virtual resultou somente em relações "superficiais" ou "falsas". A prova que tiveram 
disso foram os encontros - na realidade "real" - com os conhecidos virtuais. Foi inevitável sua decepção ao ver que, na realidade "real", aquelas pessoas não eram o que eles imaginavam através da internet. A conclusão a que os membros desse grupo chegaram foi a de que o que se passava na realidade virtual era quase sempre mentira. Para haver a verdade, eles esperavam que não houvesse o hiato entre o real e o virtual, ou seja, esperavam que as pessoas que eles conheciam na internet fossem iguais dentro e fora da rede. Isso, no entanto, não aconteceu.

Dito de outro modo, para os integrantes do primeiro grupo, alguém não pode, sem mentir, parecer um na realidade virtual e outro na realidade "real". Isso significa que os membros desse grupo esperavam que seus "amigos virtuais" se apresentassem de forma semelhante na rede e fora dela. Possivelmente, tinham essa expectativa porque eles próprios se mostram - ou se sentem - da mesma forma fora e dentro da rede.

Esses resultados indicam, portanto, que os membros do primeiro grupo se vêem como sempre sendo os mesmos, isto é, suas "formas de ser" parecem permanecer iguais na rede, fora dela e, possivelmente, em outras esferas de sua vida cotidiana. Tal visão, por sua vez, sugere que eles provavelmente têm uma sensação de unidade e de estabilidade em relação a si mesmos.

A sensação de estabilidade subjetiva que esses sujeitos parecem experimentar assemelha-se ao que Jameson chamou de centralidade do eu ou de "miragem" de centralidade do eu (Jameson, 1997, p. 42) e Turkle denominou de selves únicos e centrados (características que ambos consideram típicas do sujeito da modernidade).

Há, assim, fortes indicações de afinidade entre as características da subjetividade moderna, tal como descrita por Jameson e Turkle, e as características subjetivas que pudemos captar dos membros desse primeiro grupo.

E o segundo grupo? O que nossos resultados revelam a seu respeito?

\section{Segundo grupo: uma nova subjetividade fragmentada ou multiplicada?}

Os membros do segundo grupo, do mesmo modo que os sujeitos do primeiro, sentem-se mais desinibidos na rede do que fora dela. Sabem que, na rede, as pessoas dizem o que querem a respeito de si próprias. Isso vale para eles e, obviamente, para aqueles com quem entram em contato. Os sujeitos do segundo grupo, entretanto, não se incomodam com o fato de seus interlocutores poderem criar personagens que pouco têm a ver com o que são na vida "real". Ao contrário, vêem, nessa criação, uma nova forma de conhecer pessoas sem os preconceitos ou julgamentos apriorísticos que o encontro físico instiga. Não se importam, também, com o hiato que existe entre conhecer uma pessoa na realidade "real" e na realidade virtual. Não tomam esse hiato como prova de que as pessoas mentem na internet.

Na realidade, para os membros do segundo grupo, ao contrário do que acontece no caso dos membros do primeiro, uma pessoa se apresentar de um modo na rede e de outro fora dela não significa que exista alguma farsa. Seus depoimentos deixam claro que, para eles, é fácil lidar com o hiato entre a rede e a realidade "real". Eles parecem tomar como verdade tudo o que se passa dentro ou fora da rede. Isso provavelmente acontece porque, como já mencionado, esses sujeitos também se sentem - ou se apresentam - de forma diferente na internet e fora dela.

Assim, ao contrário dos membros do primeiro grupo, os membros do segundo grupo 
admitem a possibilidade de se verem como muitos e não como um só. Eles podem ser, ao mesmo tempo, sujeitos arrogantes e polêmicos quando usam um nick e comportados profissionais fora da rede, como é o caso de Sr. Mistério. Podem, também, ser pessoas contidas na realidade "real" e, na rede, experimentar ser divertidas e brincalhonas, como acontece com Margot.

Dado que o principal objetivo deste artigo é o de refletir sobre as transformações na subjetividade contemporânea, esse grupo tem certamente mais a nos dizer do que o primeiro. Na realidade, tomando por base os modelos propostos por Jameson e Turkle, as características subjetivas dos membros do segundo grupo nos fazem perguntar qual o grau de afinidade que apresentam em relação a cada um desses modelos. Passemos a essa discussão.

Não há dúvidas de que os resultados de nossa pesquisa são muito mais condizentes com o modelo de sujeito que transita entre múltiplos selves, proposto por Turkle, do que com o do sujeito fragmentado de Jameson. Nossos entrevistados - mesmo aqueles que, como Morpheus e o Sr. Mistério, demonstram ter diversos personagens online - passam de um personagem para outro com facilidade, mas mantêm a unidade e a coerência de cada um desses personagens.

Além disso, há várias semelhanças entre os depoimentos por nós colhidos e aqueles registrados por Turkle, semelhanças essas que são surpreendentes dadas as grandes diferenças existentes entre os contextos culturais nos quais foram realizadas as duas pesquisas. Seguem-se dois exemplos (pedimos ao leitor que perdoe a repetição de alguns).

Um dos participantes da pesquisa de Turkle faz uma afirmação radical: "Eu divido a minha mente. (...) Eu posso me ver como sendo dois ou três ou mais. E eu só ligo uma parte da minha mente e depois outra quando eu vou de janela a janela" (Turkle, 1997, p. 13, nossa tradução). A despeito de sua radicalidade, esse depoimento encontra eco em alguns trechos da entrevista de Sr. Mistério, nos quais este relata seus passeios entre um e outro nick:

"O primeiro [nick] foi White (...). White era sério e professoral. O segundo, Grouxo. O oposto de White. Caótico. Polêmico e incrível! - bem-humorado, debochado, sacana. O atual, Sr. Mistério, surgiu de uma discussão que resultou na morte do Grouxo. (...) Tb tenho outros nicks, mas, como ainda estão em uso, é melhor não divulgar..." (Sr. Mistério, 32 anos, professor universitário).

Outra entrevistada de Turkle relata o quanto se sente mais desinibida quando está online do que quando está offline: “Eu não menti para ele sobre nada específico, mas eu me sinto muito diferente online. Eu sou muito mais extrovertida, menos inibida. Eu diria que me sinto mais eu mesma" (Turkle, 1997, p. 179, nossa tradução).

Testemunho análogo é dado por um de nossos entrevistados:

“Eu não invento personagens na rede, me sinto muito à vontade para ser eu, mais do que na vida aqui fora. Eu é que fico diferente diante desse outro na rede. não sei se as pessoas me recebem diferentemente na NET, eu é que me sinto menos tolhido ou cobrado diante do outro" (Quinhodantas, 24 anos, psicólogo).

Não é à toa que Turkle, embora se inspirando em Jameson, recorre a uma patologia diferente daquela usada por este. O fato é que, como já foi discutido, Jameson chegou ao seu modelo através do procedimento de transpor características macro (sociais) para o plano micro (psicológico). Esse procedimento pouco convencional, portanto, não tem como base 
observações sistemáticas do funcionamento cotidiano de homens e mulheres de carne e osso (pois esse não era seu objetivo).

Turkle, em contrapartida, realizou um extenso e aprofundado trabalho de pesquisa com sujeitos que fazem uso daqueles que, a seu ver, são ícones da pós-modernidade: os computadores e a internet. Seus resultados, tal como os nossos, referem-se, portanto, àquilo que foi observado bem como àquilo que pode ser inferido a partir dos depoimentos de homens e mulheres que vivem intensamente o dia-a-dia contemporâneo. Talvez por isso mesmo, tanto os resultados de Turkle quanto os nossos resultados majoritários - aqueles referentes ao segundo grupo - sugerem que esses homens e mulheres se multiplicam em selves unitários, que existem ao mesmo tempo e podem entrar em ação a qualquer momento. Nem na pesquisa de Turkle nem na nossa puderam ser detectados indícios da fragmentação que Jameson alega caracterizar a subjetividade contemporânea.

Há, porém, um sério problema no que se refere ao livre trânsito entre selves unitários e simultâneos. Esse problema pode ser ilustrado com um recurso sugerido pela própria Turkle. Como mencionado anteriormente, segundo ela, é possível fazer-se uma analogia entre esses selves unitários e simultâneos e o sistema operacional Windows, usado nos computadores pessoais. Turkle lembra que, quando utilizamos o Windows, freqüentemente abrimos várias "janelas" simultâneas para diferentes finalidades: digitar um texto, fazer uma planilha, receber e-mails, navegar na internet, etc. Podemos, por exemplo, estar em um programa de batepapo e ter abertos, na tela do computador, vários outros programas, que podemos acionar com a rapidez de um clique do mouse. Dessa forma, é possível se passar da sala de bate-papo para a planilha ou para o programa de e-mail tão facilmente que pode parecer que se está fazendo tudo ao mesmo tempo. No caso dos múltiplos selves, segundo Turkle, a naturalidade com que se pode passar de um self a outro é semelhante à naturalidade com que se passa de uma a outra janela do Windows. Assim, parece que esses selves estão sempre disponíveis.

Se, todavia, examinarmos com maior cuidado essa analogia entre o sistema do Windows e os múltiplos selves, logo constataremos que algo em comum é pressuposto por ambos: alguém, ou alguma instância, que tome a decisão de clicar o mouse para passar de uma janela para outra ou que, analogamente, "decida" passar de um self para outro. $\mathrm{Na}$ realidade, isso fica bastante claro em vários dos depoimentos citados acima, em que os entrevistados - os de Turkle e os nossos - usam o pronome eu repetidas vezes ao descrever como passam de uma tela para outra ou de um personagem para outro. Talvez um dos melhores exemplos seja a já citada fala que deu origem ao título deste artigo: "Eu divido a minha mente. (...) Eu posso me ver como sendo dois ou três ou mais. E eu só ligo uma parte da minha mente e depois outra quando eu vou de janela a janela" (Turkle, 1997, p. 13, nossa tradução).

Essa observação indica que a subjetividade contemporânea realmente parece ser caracterizada por selves múltiplos. Diferentemente do que alega Turkle quando fala de descentramento, no entanto, algum desses selves deve ser predominante para ter o poder de decisão sobre o que vai ser feito. A pergunta que imediatamente se coloca é: não seria esse self predominante o correspondente contemporâneo da instância centralizadora que caracterizava a subjetividade moderna?
"Eu posso me ver como sendo dois ou três ou mais. $E$ eu só ligo uma parte da minha mente e depois outra quando eu vou de janela a janela" (Turkle, 1997, p. 13, nossa tradução)". 
Uma segunda pergunta também se coloca. Tendo-se em vista o fato de que Turkle é uma psicóloga experiente, como isso the passou despercebido? E aqui entra um segundo problema, ao qual tanto Turkle quanto Jameson deram pouca atenção: o uso de modelos patológicos como ponto de partida para a descrição de um novo tipo de organização subjetiva saudável. Examinemos esse ponto em maior detalhe.

O uso de classificações psiquiátricas clássicas para descrever a organização subjetiva atual talvez não gerasse nenhum tipo de problema se Turkle e Jameson, como muitos outros autores contemporâneos (ver, por exemplo, Baudrillard, 1997; Birman, 2003), estivessem interessados em dizer que a subjetividade pósmoderna é, de modo geral, patológica. Esse não é, contudo, o ponto de vista adotado por Jameson e Turkle. O objetivo de ambos os autores é, admitidamente, o de descrever positivamente um novo tipo de subjetividade. Ambos, no entanto, paradoxalmente, lançam mão de modelos patológicos e depois tentam "despatologizá-los", ou seja, tentam descartar a patologia e ficar com as características desses quadros (os chamados "sintomas").

Essa tarefa, todavia, é bastante complicada. Minimamente porque palavras como "esquizofrenia" ou "transtorno de personalidade múltipla" remetem imediatamente a um mesmo campo semântico - o da patologia - que é incompatível com a busca de descrição de algo que pertence ao campo semântico da saúde. Ainda que algumas características desses quadros possam ser interessantes, usar modelos patológicos sem sua patologia intrínseca pressupõe que tais características possam ser neutras, ou seja, que elas existam à parte da patologia, quando, na verdade, elas fazem parte da patologia.

Há ainda um último ponto a ser explorado em relação à utilização da esquizofrenia e do transtorno de personalidade múltipla como metáforas. Ainda que não tivessem a conotação de patologia, essas metáforas, cujo significado já está cristalizado e enrijecido pelo hábito, transmitem idéias difíceis de desconstruir. Já é quase impossível, diríamos, conseguir elaborar novas reflexões sobre um novo sujeito usando metáforas antigas, quanto mais metáforas antigas com conotações patológicas indeléveis.

\section{Uma subjetividade à espera de novos estudos}

Como diz Harvey, "nunca é fácil elaborar uma avaliação crítica de uma situação avassaladoramente presente" (Harvey, 1999, p. 301).

Caracterizar a subjetividade contemporânea é, como acabamos de ver, uma tarefa extremamente árdua e de difícil sucesso. Temos pouca distância das transformações ainda em curso (nas quais nós próprios estamos imersos) para que uma lógica diferente daquela à qual estávamos acostumados faça sentido a ponto de encontrarmos nomenclaturas novas e adequadas ao invés de metáforas antigas e aprisionantes.

Tanto Jameson quanto Turkle fizeram excelentes tentativas com as melhores intenções. Esbarraram, no entanto, com os mais persistentes obstáculos no caminho da apreensão daquilo que é novo: as velhas formas de olhar o mundo e seus habitantes, formas essas sempre cristalizadas na linguagem.

Pode-se dizer que - dada a distância que já temos em relação à era moderna - ambos tiveram mais sucesso na descrição do sujeito da modernidade do que na apreensão do sujeito contemporâneo.

Não nos deixemos enganar, no entanto. Seus modelos tiveram o mérito de chamar a atenção de muitos para o fato de que há uma nova organização subjetiva a ser estudada em sua positividade. Há muito trabalho pela frente para quem quer que esteja interessado. 
ANDERSON, P. As Origens da Pós-Modernidade. Rio de Janeiro: Jorge Zahar Editor, 1998.

BIRMAN, J. Soberania, Crueldade e Servidão: Mal-estar, Subjetividade e Projetos Identitários na Modernidade. In T. Pinheiro (org). Psicanálise e Formas de Subjetivação Contemporâneas.

Rio de Janeiro: Contra-Capa, 2003, pp. 11-23.

BAUDRILLARD, J. Tela Total:Mito-ironias da Era do Virtual e da Imagem. Porto Alegre: Sulina, 1997.

BAUMAN, Z. O Mal-Estar na Pós-Modernidade. Rio de Janeiro: Jorge Zahar Editor, 1998.

CALLIGARIS, C. Introdução a uma Clínica Diferencial das Psicoses. Porto Alegre: Artes Médicas, 1989

CASTELLS, M. A Sociedade em Rede. São Paulo: Paz e Terra, 1999

GIDDENS, A. A Vida em uma Sociedade Pós-industrial. In U. Beck, U., A. Giddens \& S. Lash, Modernização Reflexiva: Política, Tradição e Estética na Ordem Social Moderna. São Paulo: Editora da Universidade Estadual Paulista, 1995, pp. 73-133.

HARVEY, D. Condição Pós-Moderna. São Paulo: Edições Loyola, 1999

JAMESON, F. Pós-Modernismo: a Lógica Cultural do Capitalismo Tardio. São Paulo: Editora Ática, 1997.

Espaço e Imagem: Teorias do Pós-moderno e outros Ensaios. Rio de Janeiro: Editora UFRJ, 1995.

O Pós-modernismo e a Sociedade de Consumo. In E. Ann Kaplan (org ) O Mal-Estar no Pós-Modernismo: Teorias, Práticas. Rio de Janeiro: Jorge Zahar Editor, 1993, pp. 25-44.

LACAN, J. Escritos. Rio de Janeiro: Jorge Zahar Editor, 1998.

O Seminário 3: as Psicoses. Rio de Janeiro: Jorge Zahar Editor, 1985

LEITÃO, C. Os Impactos Subjetivos da Internet: Reflexões Teóricas e Clínicas. Tese de Doutorado em Psicologia Clínica.
Daniela Romão-Dias

Psicóloga, Mestre em Psicologia Clínica pela PUC-Rio, doutoranda em Psicologia Clínica da PUC-Rio.

Ana Maria Nicolaci-da-Costa Psicóloga, Ph.D em Psicologia pela Universidade de Londres, professora e pesquisadora da PUC-Rio.

Departamento de Psicologia - Rua Marquês de São Vicente, 225 - Gávea - 22543-900 -

Rio de Janeiro - RJ - Tel. (21) 3114-1183 /

3114-1185 FAX(21) 3114-1187

E-mail: danirom@globo.com
Pontifícia Universidade Católica do Rio de Janeiro, Rio de Janeiro, 2003.

LEITÃO, C. e NICOLACI-DA-COSTA, A. M. A Psicologia no Novo Contexto Mundial. Estudos de Psicologia (Natal), volume 8, número 3, 2003, pp. 421-430.

LÉVY,P. As Tecnologias da Inteligência: o Futuro do Pensamento na Era da Informática. São Paulo: Editora 34, 1998.

O que É o Virtual? São Paulo: Editora 34, 1996.

LOPES, L. C. A Informação: a Mônada do Século XX. In Ciberlegenda, no 1. www.uff.br/mestcii/lclop2.htm., 1998.

YYOTARD, J. F. A Condição Pós-Moderna. Rio de Janeiro: José Olympio Editora, 1998.

NICOLACI-DA-COSTA, A. M. Na Malha da Rede: os Impactos Íntimos da Internet. Rio de Janeiro: Campus, 1998.

A Análise de Discurso em Questão. In Psicologia: Teoria Pesquisa, vol. 10, número 2, 1994, pp. 317-331.

Questões Metodológicas sobre a Análise de Discurso. In Psicologia: Reflexão e Crítica, vol. 4, números 1/2, 1989, pp. 103-108.

NISBET, R. A. The Sociological Tradition. New York: Basic Books, Inc, 1966.

PANKOW, G. O Homem e sua Psicose. Campinas: Papirus, 1989

ROMÃO-DIAS, D. Nossa Plural Realidade: um Estudo sobre a Subjetividade na Era da Internet. Dissertação de Mestrado em Psicologia Clínica. Pontifícia Universidade Católica do Rio de Janeiro, Rio de Janeiro, 2001.

SENNETT, R. A Corrosão do Caráter: Conseqüências Pessoais do Trabalho no Novo Capitalismo. Rio de Janeiro: Record, 1999.

TURKLE, S. Life on the Screen: Identity in the Age of the Internet New York: Toutchstone, 1997.

ATTIMO, G. O Fim da Modernidade: Niilismo e Hermenêutica na Cultura Pós-moderna. São Paulo: Martins Fontes, 1996. 